\title{
Cryptococcus surugaensis sp. nov., a novel yeast species from sediment collected on the deep-sea floor of Suruga Bay
}

\author{
Takahiko Nagahama, ${ }^{1}$ Makiko Hamamoto, ${ }^{2}$ Takashi Nakase, ${ }^{3}$ \\ Yoshihiro Takaki ${ }^{1}$ and Koki Horikoshi ${ }^{1}$ \\ ${ }^{1}$ Deep-sea Microorganism Research Group, Japan Marine Science and Technology Center \\ (JAMSTEC), 2-15 Natsushima-cho, Yokosuka 237-0061, Japan
${ }^{2,3}{ }^{3}$ hemical Genetics Laboratory ${ }^{2}$ and Japan Collection of Microorganisms ${ }^{3}$, RIKEN, Wako, Saitama 351-0198, Japan

Takahiko Nagahama nagahama@jamstec.go.jp

\begin{abstract}
A novel species of the genus Cryptococcus was isolated from sediment collected on the deep-sea floor of Suruga Bay, Japan. Nucleotide sequences of 18S rDNA, internal transcribed spacers, $5 \cdot 8 \mathrm{~S}$ rDNA and the D1/D2 region of $26 \mathrm{~S}$ rDNA of strain SY $-260^{\top}$ suggested affinities to a phylogenetic lineage that includes Cryptococcus luteolus. Comparisons of the rDNA sequences of each region clarified that strain $\mathrm{SY}-260^{\top}$ is related distantly to Bullera coprosmaensis and Bullera oryzae, but is distinct at the species level. As ballistoconidia and sexual reproduction were not observed in strain $\mathrm{SY}-260^{\top}$, this strain is described as Cryptococcus surugaensis sp. nov. (type strain, SY-260 ${ }^{\top}=\mathrm{JCM} 11903^{\top}=\mathrm{CBS} 9426^{\top}$ ).
\end{abstract}

Members of the genus Cryptococcus are reported commonly among yeasts isolated from sea water (e.g. Yamasato et al., 1974; Fell, 1976; Hagler \& Ahearn, 1987). This anamorphic genus in the Hymenomycetes is characterized mainly by the assimilation of inositol and D-glucuronate and production of starch (Fell \& Statzell-Tallman, 1998), but is known to be polyphyletic (Takashima \& Nakase, 1999; Fell et al., 2000). We isolated Cryptococcus strains in a survey of yeasts from various deep-sea floors in the north-west Pacific Ocean (Nagahama et al., 2001a). A strain from sediment collected at a depth of $2406 \mathrm{~m}$ in Suruga Bay $\left(34^{\circ} 36^{\prime} 55 \mathrm{~N}\right.$, $138^{\circ} 34^{\prime} 77 \mathrm{E}$; temperature, $3^{\circ} \mathrm{C}$ ) is described here as a novel yeast species of the genus Cryptococcus.

\section{Sample collection and isolation}

Samples were collected from Suruga Bay by using an unmanned submersible vessel without contamination by open water, as described previously (Takami et al., 1997; Nagahama et al., 2001a). Yeasts were isolated from fresh deep-sea sediments and cultured on YM agar, 1/5 YM agar, potato dextrose agar, cornmeal agar or marine agar (all from Difco), dissolved in artificial sea water supplemented with $0.01 \%$ chloramphenicol. Agar plates were incubated

Published online ahead of print on 27 June 2003 as DOI 10.1099/ ijs.0.02712-0.

Abbreviations: ITS, internal transcribed spacer; ML, maximum-likelihood. The GenBank/EMBL/DDBJ accession number for the 18S rDNA, D1/ $\mathrm{D} 2$ region of $26 \mathrm{~S}$ rDNA and internal transcribed spacer sequences of $\mathrm{SY}-260^{\top}$ is $\mathrm{AB} 100440$. at low temperature $\left(5-10{ }^{\circ} \mathrm{C}\right)$ for the first 2 weeks and then at $20{ }^{\circ} \mathrm{C}$ for 1 month.

\section{Physiological and biochemical characteristics}

Strains were characterized morphologically and physiologically by using standard methods with some modifications (Yarrow, 1998). Assimilation of nitrogen compounds was examined on solid media by using a starved inoculum (Nakase \& Suzuki, 1986). Vitamin requirements were investigated according to the method of Komagata \& Nakase (1967). Ubiquinones were extracted by the method of Yamada \& Kondo (1973) with slight modifications and determined by HPLC as described previously (Hamamoto \& Nakase, 1995). DNA was extracted and purified following the procedure described by Hamamoto \& Nakase (1995) and DNA base composition was determined by using the HPLC method of Tamaoka \& Komagata (1984).

\section{Phylogenetic analysis}

DNA extraction for PCR was performed by using a QIAamp DNeasy Tissue kit (Qiagen) with some modifications (Nagahama et al., 2001b). Primers used for amplification and sequencing of the $18 \mathrm{~S}$ rDNA, $5 \cdot 8 \mathrm{~S}$ rDNA and internal transcribed spacer (ITS) regions were those described by White et al. (1990); primers for the D1/D2 region of 26S rDNA were those described by Fell et al. (2000). PCR products were purified by using ExoSAP-IT (USB) and sequenced by using a model 4000L (LI-COR) or MegaBACE 1000 (Pharmacia) DNA sequencer. 
All sequences were aligned by using CLUSTAL W 1.81 (Thompson et al., 1994) and adjusted manually. Positions where one or more species contained a length mutation and a region that was aligned ambiguously were not included in subsequent phylogenetic analysis. Phylogenetic trees were constructed by utilizing the maximum-likelihood (ML) method (Felsenstein, 1981) with the optimal Ts/Tv ratio of the HKY85 model (Hasegawa et al., 1985), estimated from the neighbour-joining tree (Saitou \& Nei, 1987) in PAUP 4.0b8 (Swofford, 1998). This tree was derived by a heuristic search with random stepwise addition of 100 replicates. Robustness of branches in the tree was evaluated by bootstrap analysis (Felsenstein, 1985) with 100 resamplings.

Sequences of the 18S rDNA, $26 \mathrm{~S}$ rDNA, 5.8S rDNA and ITS regions of SY- $260^{\mathrm{T}}$ were deposited in GenBank/ DDBJ under accession number AB100440.

\section{Phylogenetic position of strain SY-260 ${ }^{\top}$ isolated from deep-sea sediment}

We sequenced a DNA fragment of strain $S Y-260^{\mathrm{T}}$ that included $18 \mathrm{~S}$ rDNA, ITS1, 5.8S rDNA, ITS2 and the D1/ $\mathrm{D} 2$ region of $26 \mathrm{~S}$ rDNA. This sequence had some affinity to that of species in the Cryptococcus luteolus lineage (Takashima \& Nakase, 1999) or Luteolus clade (Scorzetti et al., 2002).

The relationship between members of this group and strain SY $-260^{\mathrm{T}}$ was estimated, based on $2077 \mathrm{bp}$ in the $18 \mathrm{~S}$ rDNA, $5 \cdot 8 \mathrm{~S}$ rDNA and ITS regions (Fig. 1). Overall, this branching order was statistically robust and consistent with those based on $18 \mathrm{~S}$ rDNA in the phylogenetic tree drawn by Bai et al. (2001a, b). Species used in this study were divided into the subclades Luteolus, Mrakii and Dioszegia (Fig. 1),

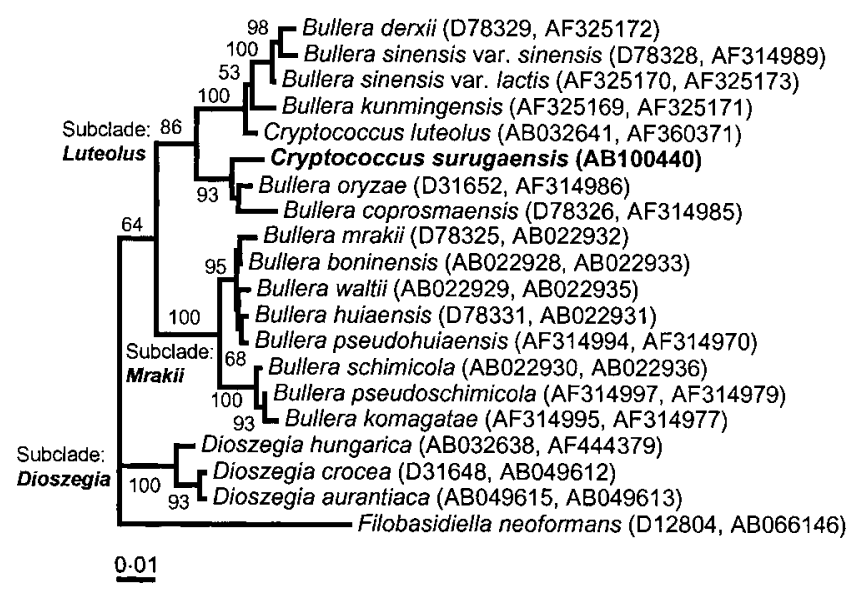

Fig. 1. Phylogenetic tree within the $C$. luteolus lineage on the basis of 2077 aligned nucleotide sites in 18S rDNA, ITS and $5.8 S$ rDNA. The ML tree with the HKY85 model (Ts/Tv, $1 \cdot 175931)$ was constructed as described in the text. Numbers are bootstrap values for nodes supported by $>50 \%$ (100 replicates). Bar, 0.01 substitutions per site. which were supported strongly by bootstrap values. Strain SY $-260^{\mathrm{T}}$ was obviously placed into the subclade Luteolus. Strain SY $-260^{\mathrm{T}}$ and two Bullera species, Bullera coprosmaensis and Bullera oryzae, formed a cluster that was separate from the other members of the subclade Luteolus. The subclade Mrakii, which consists of eight Bullera species, is relatively coherent with the subclade Luteolus. These two subclades appeared to be related to each other and were separate from the subclade Dioszegia.

The phylogenetic tree of species in the Luteolus subclade with nine undescribed species of Cryptococcus based on $603 \mathrm{bp}$ in the D1/D2 region of the 26S rDNA sequences (Fig. 2) had few branches that were supported strongly by bootstrap values and appeared to be relatively ambiguous for the 18S-ITS tree drawn above. Two species with identical sequences, Bullera derxii and Bullera sinensis var. sinensis, differed from B. sinensis var. lactis at only one base, although these three species were well-differentiated based on $18 \mathrm{~S}$ rDNA and ITS sequences. The relationship between strain SY $-260^{\mathrm{T}}$, B. coprosmaensis and B. oryzae was uncertain in this tree, in contrast to that in the 18S-ITS tree. This disagreement seemed to be caused by the remarkably long lineage of Cryptococcus sp. CBS 8369, as a tree that excluded CBS 8369 supported the cluster of strain SY $-260^{\mathrm{T}}$ with the two Bullera species. In the nine strains of undescribed Cryptococcus species, CBS 8356 and CBS 8367 were identical to Bullera kunmingensis. The seven remaining strains were divided into three groups and each appeared to qualify as a novel species.

The closest species to strain SY $-260^{\mathrm{T}}$ in each rDNA sequence region were not identical. They were B. oryzae in the $18 \mathrm{~S}$, $5 \cdot 8 \mathrm{~S} \mathrm{rDNA}$ and ITS2 regions, B. coprosmaensis in the ITS1

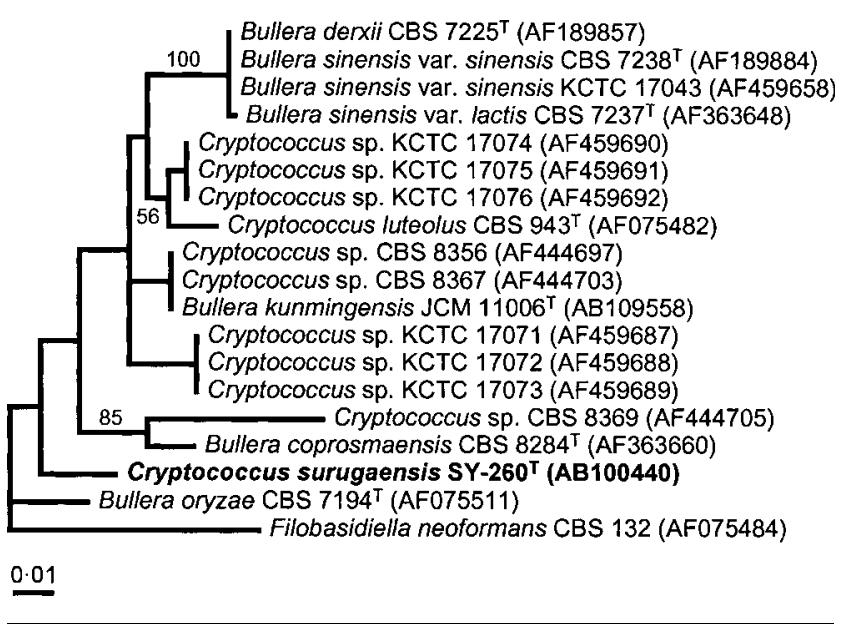

Fig. 2. Phylogenetic tree of $C$. surugaensis and related species on the basis of 603 aligned nucleotide sites in the D1/D2 region of $26 \mathrm{~S}$ rDNA. The ML tree with the HKY85 model (Ts/ Tv, 3.136150) was constructed as described in the text. Numbers are bootstrap values for nodes supported by $>50 \%$ (100 replicates). Bar, 0.01 substitutions per site. 
region and $B$. sinensis var. lactis in the D1/D2 region. Nucleotide substitutions of $0.6 \%$ in the $18 \mathrm{~S}$ and $5.8 \mathrm{~S}$ rDNA, $13 \cdot 4 \%$ in the ITS1, $10.5 \%$ in the ITS2 and $4 \cdot 5 \%$ in the D1/D2 regions between strain SY $-260^{\mathrm{T}}$ and its most closely related species indicated that this strain is sufficiently separated from known species. Differences of $<1 \%$ in the D1/D2 region or of $1-2 \%$ in ITS sequences were generally recognized to correspond to the borderline between conspecific and different species (Fonseca et al., 2000; Fell et al., 2000; Bai et al., 2001a, 2001b; Hamamoto et al., 2002; Nagahama et al., 2003).

\section{Comparison of physiological and biochemical characteristics between strain $S Y-260^{\top}$ and related species}

Phylogenetically, the species most closely related to strain SY- $260^{\mathrm{T}}$ was considered to be B. oryzae (Fig. 1) but their DNA $G+C$ contents had differences of $>10 \%$, whereas B. coprosmaensis had a DNA G $+\mathrm{C}$ content similar to that of strain SY- $260^{\mathrm{T}}$. The evolutionary distances among these three species appear to be too great to estimate relationships based on G $+C$ contents. Strain SY $-260^{\mathrm{T}}$ can be discriminated physiologically from B. coprosmaensis and B. oryzae, based on the assimilation of L-sorbose and soluble starch. As ballistoconidia and sexual reproduction were not observed in strain SY- $260^{\mathrm{T}}$, we describe this strain as a novel species of the genus Cryptococcus.

\section{Latin diagnosis of Cryptococcus surugaensis sp. nov. Nagahama, Hamamoto et Nakase}

In medio liquido YM post 3 dies ad $25^{\circ} \mathrm{C}$, cellulae ovoideae vel ellipsoidae $(2-4 \times 2-7 \mu \mathrm{m})$, singulae aut binae. Post unum mensem pellicula fragilis et sedimentum formantur. Cultura in agaro $\mathrm{YM}$ ad $25^{\circ} \mathrm{C}$, subflava, nitida, mollis et margine glabra. Hyphae et pseudohyphae non formantur. Fermentatio nulla. Glucosum, galactosum, L-sorbosum, saccharosum, maltosum, cellobiosum, trehalosum, melibiosum, raffinosum, melezitosum, D-xylosum, L-arabinosum, D-arabinosum, Dribosum, L-rhamnosum, glycerolum, erythritolum, ribitolum (exiguum), galactitolum, D-mannitolum, D-glucitolum (exiguum), methyl- $\alpha$-D-glucosidum, salicinum (exiguum), glucono- $\delta$-lactonum, acidum 2-ketogluconicum, acidum 5-ketogluconicum, acidum DL-lacticum, acidum succinicum, acidum citricum et inositolum assimilantur, at non lactosum, inulinum, amylum solubile, ethanolum, acidum D-glucuronicum nec acidum D-galacturonicum. Ethylaminum, lysinum et cadaverinum assimilantur at non kalium nitricum nec natrium nitrosum. Maxima temperatura crescentiae: 31-34 ${ }^{\circ} \mathrm{C}$. Ad crescentiam vitaminum non necessarium est. Materia amyloidea iodophila formantur. G + C acidi deoxyribonucleati $48 \cdot 3 \mathrm{~mol} \%$ (per HPLC). Ubiquinonum majus Q-10.

Typus stirps SY $-260^{\mathrm{T}}$ ex sedimentum, Suruga Bay, Japan, isolata est. In collectionibus culturarum quas Japan Collection of Microorganisms, Wako, Saitama, Japan, sustentant, no. JCM $11903^{\mathrm{T}}\left(=\mathrm{CBS} 9426^{\mathrm{T}}\right)$ deposita est.

\section{Description of Cryptococcus surugaensis sp. nov. Nagahama, Hamamoto \& Nakase}

Cryptococcus surugaensis (su.ru.ga.en'sis. N.L. masc. adj. surugaensis referring to the geographical origin of the species).

In YM broth (Difco) after 3 days culture at $25^{\circ} \mathrm{C}$, cells are ovoidal to ellipsoidal $(2-4 \times 2-7 \mu \mathrm{m})$ and occur singly or in parent-bud pairs. A sediment and fragile pellicle are formed after 1 month. After 1 month on YM agar at $25^{\circ} \mathrm{C}$, streak culture is light yellow, glistening, soft and has an entire margin. In Dalmau plate cultures on cornmeal agar (Difco), no branching hyphae or pseudohyphae are formed. Fermentation ability is negative. The following carbon compounds are assimilated: D-glucose, galactose, L-sorbose, sucrose, maltose, cellobiose, trehalose, melibiose, raffinose, melezitose, D-xylose, L-arabinose, D-arabinose, D-ribose, L-rhamnose, glycerol, erythritol, ribitol (weak), galactitol, D-mannitol, D-glucitol (weak), methyl $\alpha$-D-glucoside, salicin (weak), glucono- $\delta$-lactone, 2-ketogluconic acid, 5ketogluconic acid, DL-lactic acid, succinic acid, citric acid and inositol; no growth occurs on lactose, inulin, soluble starch, ethanol, D-glucuronic acid or D-galacturonic acid. The nitrogen compounds ethylamine, lysine and cadaverine are assimilated. No growth occurs on potassium nitrate or sodium nitrite. Maximum temperature for growth is $31-34^{\circ} \mathrm{C}$. Vitamins are not required for growth. No growth occurs on $50 \%$ glucose/yeast extract agar. Growth occurs in the presence of 100 p.p.m. cycloheximide. Growth in the presence of $10 \%$ sodium chloride is negative. Starch-like substances are produced. Diazonium blue B reaction is positive. Urease activity is positive. $\mathrm{G}+\mathrm{C}$ content of nuclear DNA is $48 \cdot 3 \mathrm{~mol} \%$ (by HPLC). Major ubiquinone is Q- 10 .

The type strain of C. surugaensis, SY- $260^{\mathrm{T}}$, was isolated from sediments collected from the deep-sea floor of Suruga Bay, Japan. This strain has been deposited in the Japan Collection of Microorganisms, Saitama, Japan, as JCM $11903^{\mathrm{T}}\left(=\right.$ CBS $\left.9426^{\mathrm{T}}\right)$.

\section{Acknowledgements}

We thank Dr Y. Nogi for his useful suggestions on technical problems. We are indebted to Dr D. Honda for his skilful advice on phylogenetic analysis using PAUP* 4.0.

\section{References}

Bai, F.-Y., Takashima, M. \& Nakase, T. (2001a). Description of Bullera kunmingensis sp. nov., and clarification of the taxonomic status of Bullera sinensis and its synonyms based on molecular phylogenetic analysis. FEMS Yeast Res 1, 103-109.

Bai, F.-Y., Takashima, M. \& Nakase, T. (2001b). Phylogenetic analysis of strains originally assigned to Bullera variabilis: descriptions of Bullera pseudohuiaensis sp. nov., Bullera komagatae sp. nov. and Bullera pseudoschimicola sp. nov. Int J Syst Evol Microbiol 51, 2177-2187. 
Fell, J. W. (1976). Yeasts in oceanic regions. In Recent Advances in Aquatic Mycology, pp. 93-124. Edited by E. B. G. Jones. London: Elek Science.

Fell, J. W. \& Statzell-Tallman, A. (1998). Cryptococcus Vuillemin. In The Yeasts, a Taxonomic Study, 4th edn, pp. 742-767. Edited by C. P. Kurtzman \& J. W. Fell. Amsterdam: Elsevier.

Fell, J. W., Boekhout, T., Fonseca, A., Scorzetti, G. \& StatzellTallman, A. (2000). Biodiversity and systematics of basidiomycetous yeasts as determined by large-subunit rDNA D1/D2 domain sequence analysis. Int J Syst Evol Microbiol 50, 1351-1371.

Felsenstein, J. (1981). Evolutionary trees from DNA sequences: a maximum likelihood approach. J Mol Evol 17, 368-376.

Felsenstein, J. (1985). Confidence limits on phylogenies: an approach using the bootstrap. Evolution 39, 783-791.

Fonseca, Á., Scorzetti, G. \& Fell, J. W. (2000). Diversity in the yeast Cryptococcus albidus and related species as revealed by ribosomal DNA sequence analysis. Can J Microbiol 46, 7-27.

Hagler, A. N. \& Ahearn, D. G. (1987). Ecology of aquatic yeasts. In The Yeasts, 2nd edn, vol. 1, pp. 181-205. Edited by A. H. Rose \& J. S. Harrison. London: Academic Press.

Hamamoto, M. \& Nakase, T. (1995). Ballistosporous yeasts found on the surface of plant materials collected in New Zealand. 1. Six new species in the genus Sporobolomyces. Antonie van Leeuwenhoek 67, 151-171.

Hamamoto, M., Nagahama, T. \& Tamura, M. (2002). Systematic study of basidiomycetous yeasts - evaluation of the ITS regions of rDNA to delimit species of the genus Rhodosporidium. FEMS Yeast Res 2, 409-413.

Hasegawa, M., Kishino, H. \& Yano, T. (1985). Dating of the humanape splitting by a molecular clock of mitochondrial DNA. J Mol Evol 22, 160-174.

Komagata, K. \& Nakase, T. (1967). Reitoshokuhin no biseibutsu ni kansuru kenkyu. V. Shihan reitoshokuhin yori bunri shita kobo no seijo (microbiological studies on frozen foods). Shokuhin Eiseigaku Zasshi 8, 53-57 (in Japanese).

Nagahama, T., Hamamoto, M., Nakase, T., Takami, H. \& Horikoshi, K. (2001a). Distribution and identification of red yeasts in deep-sea environments around the northwest Pacific Ocean. Antonie van Leeuwenhoek 80, 101-110.

Nagahama, T., Hamamoto, M., Nakase, T. \& Horikoshi, K. (2001b). Rhodotorula lamellibrachii sp. nov., a new yeast species from a tubeworm collected at the deep-sea floor in Sagami Bay and its phylogenetic analysis. Antonie van Leeuwenhoek 80, 317-323.

Nagahama, T., Hamamoto, M., Nakase, T. \& Horikoshi, K. (2003). Rhodotorula benthica sp. nov. and Rhodotorula calyptogenae sp. nov., novel yeast species from animals collected from the deep-sea floor, and Rhodotorula lysiniphila sp. nov., which is related phylogenetically. Int J Syst Evol Microbiol 53, 897-903.

Nakase, T. \& Suzuki, M. (1986). Bullera megalospora, a new species of yeast forming large ballistospores isolated from dead leaves of Oryza sativa, Miscanthus sinensis, and Sasa sp. in Japan. J Gen Appl Microbiol 32, 225-240.

Saitou, N. \& Nei, M. (1987). The neighbor-joining method: a new method for reconstructing phylogenetic trees. Mol Biol Evol 4, 406-425.

Scorzetti, G., Fell, J. W., Fonseca, A. \& Statzell-Tallman, A. (2002). Systematics of basidiomycetous yeasts: a comparison of large subunit D1/D2 and internal transcribed spacer rDNA regions. FEMS Yeast Res 2, 495-517.

Swofford, D. L. (1998). PAUP*: phylogenetic analysis using parsimony ( ${ }^{*}$ and other methods), version 4.0. Sunderland, MA: Sinauer Associates.

Takami, H., Inoue, A., Fuji, F. \& Horikoshi, K. (1997). Microbial flora in the deepest sea mud of the Mariana Trench. FEMS Microbiol Lett 152, 279-285.

Takashima, M. \& Nakase, T. (1999). Molecular phylogeny of the genus Cryptococcus and related species based on the sequences of $18 \mathrm{~S}$ rDNA and internal transcribed spacer regions. Microbiol Cult Collect $15,35-47$.

Tamaoka, J. \& Komagata, K. (1984). Determination of DNA base composition by reverse-phase high-performance liquid chromatography. FEMS Microbiol Lett 25, 125-128.

Thompson, J. D., Higgins, D. G. \& Gibson, T. J. (1994). CLUSTAL W: improving the sensitivity of progressive multiple sequence alignment through sequence weighting, position-specific gap penalties and weight matrix choice. Nucleic Acids Res 22, 4673-4680.

White, T. J., Bruns, T., Lee, S. \& Taylor, J. W. (1990). Amplification and direct sequencing of fungal ribosomal RNA genes for phylogenetics. In PCR Protocols: a Guide to Methods and Applications, pp. 315-322. Edited by M. A. Innis, D. H. Gelfand, J. J. Sninsky \& T. J. White. San Diego, CA: Academic Press.

Yamada, Y. \& Kondo, K. (1973). Coenzyme Q system in the classification of the yeast genera Rhodotorula and Cryptococcus and the yeast-like genera Sporobolomyces and Rhodosporidium. J Gen Appl Microbiol 19, 59-77.

Yamasato, K., Goto, S., Ohwada, K., Okuno, D., Araki, H. \& lizuka, H. (1974). Yeasts from the Pacific Ocean. J Gen Appl Microbiol 20, 289-307.

Yarrow, D. (1998). Methods for the isolation, maintenance and identification of yeasts. In The Yeasts, a Taxonomic Study, 4th edn, pp. 77-100. Edited by C. P. Kurtzman \& J. W. Fell. Amsterdam: Elsevier. 